\title{
Are Sportspersons Good Moral Role Models?
}

Authors' contribution:

A) conception and design of the study

B) acquisition of data

C) analysis and interpretation of data

D) manuscript preparation

E) obtaining funding

\section{Roger Melin}

School of Humanities and Media, Sweden

\section{KEYWORDS}

\begin{abstract}
It has been thought that sportspersons, through their participation in sport, acquire moral attitudes and behavior that make them good moral role models. These moral attitudes and behavior can be called the ethos of sport, and consist of the principles of fair play and courage, justice, and honesty. In this article, it is argued that this belief is mistaken. Through four very common examples of sporting practice, it is shown that sport, contrary to providing a good basis for proper moral behavior, promotes what otherwise would be called non-moral attitudes and behavior. As a conclusion, it is pointed out that sportspersons might very well be good moral role models, but that they would be moral role models in spite of the fact that they are involved in sporting activities.

ethos of sport, role model, sporting practice
\end{abstract}

\section{Introduction}

In a football game between Lazio and Napoli in 2012 in the Italian league, the Lazio player Miroslav Klose receives a ball that he manages to put inside the opponents' net, and the referee judges it to be a goal. Klose at first celebrates the goal, but later he realizes that the decision was not correct, since he used his hand to score the goal. He informs the referee, who changes his decision and awards a free kick to the defending team due to Klose's foul play (E. Karlsson, 2012).

Klose's behavior was highly praised by many people, not only by other football players, but also by coaches, viewers, and football commentators. It was seen as a very good example of the moral standards in sport (K. Karlsson, 2012). What Klose did was showing a good sportsmanship by acting in accordance with the fair play principle in sport. What is more, he showed courage in his decision and respect and generosity towards other players, the referee, the supporters, and, in the end, football itself. In this case, Klose is a very good example that sportspersons, through their participation in sport, acquire and show good moral norms and behavior. In this way, the sporting arena is both an optimal arena for personal development of moral judgment and an optimal arena in which participators of sport, especially at the elite level, can be moral examples for others. Be fair, be respectful, be honest, be a sportsperson - this view of sport is an idea that has prevailed since the time of Plato (Plato, 1939, 1993). Today, it is strongly supported, for instance, by John Perry, who claims that there is an ethos of sport, or even an Olympic ethos of sport (Parry, 2010, pp. 316-326). It is claimed that since sport promotes sportspersons with proper moral qualities and ethical 
principles, they should also be ethical role models for others. Through their sporting participation, they acquire behavioral patterns that are generally desirable to the sport community as well as in society at large.

The aim of this project is to look closer at the idea of sportspersons being moral role models. I will problematize the idea that sportspersons, qua sportspersons, can have a special moral value for society. By describing some typical cases in sport, I will show that even if sport can be understood on one hand as promoting socially desirable behavior through the ideal of fair play, on the other hand it implicitly promotes socially undesirable behavior. The specific cases I will be looking at are: rule violations in sport, unserious participation in sport, dishonesty in sport, and derogatory language and behavior in sport.

\section{The ethos of sport: Sportspersons as moral role models}

Before starting to clarify why it is wrong to think that sportspersons ought to be understood as moral role models, we need to have some basic understanding of sport as a phenomenon, and to answer the question of why some people have interpreted sportspersons as moral role models in society.

Sport can be understood in many different ways, but for our purpose, disregarding all its external features, we can simply argue that sport is a rule-adherent social practice based upon constitutive rules, regulative rules, ethical and aesthetic evaluative rules, and norms that aim at developing excellence in relation to certain skills and through acquired excellence distinguishes between winners and losers ${ }^{1}$. According to this way of understanding sport, it becomes an arena for performance as well as for moral development. In sport, participants not only learn the rules, but also become better persons who play fairly and act in accordance with the rules of sport. Primarily, they learn and cultivate fundamental "sport values", which include sportsmanship, fair play, determination, and endurance, as sport provides circumstances where these moral goods become particularly easy to cultivate. Parry calls this the ethos of sport (Parry, 2010, pp. 316-326).

An ethos, according to Parry, is the overall spirit and ethics upheld by a certain group or community (ibid, p. 317). It consists of both the theoretical basis of meaning and values of a distinctive field of activities, as well as the practice. Parry claims it is "the distinctive character, spirit and attitudes of a group or community" (ibid, p. 317). We must assume it is somehow supervening on the basic elements of the practice in the sense that the basic attitudes, moral regulations, character, and spirit of the group are consistent with the constitutive and regulative rules of the practice. In addition, as Sigmund Loland claims, the ethos is "learned and internalized through practice" (Loland, 1998, p. 91). Furthermore, Parry points out that this specific ethos is always related to the general values of society, and the optimal case is that the ethos is consistent with the values of society as well as supported by the society (Parry, 2010, p. 319). This means that when involved in sport, we not only do sport as such, but we must understand that by learning the rules of the game, a participant is also learning the ethos of the game, in the sense that these two abilities interact. Furthermore, the acquisition of the sport ethos equals becoming a morally good person according to the standards of society. This means that sportspersons, since they have actually acquired the ethos of sport through their participation in the sporting community, can be considered to be good moral role models outside of the sporting arena as well.

The basic idea of acquiring the ethos of sport can be understood through the following phenomena: an experienced interdependence between sportspersons participating in a particular sport activity, and an expansion in which the sport activity, through its competitive aspect, becomes a part of a wider social community consisting of supporters, media, and stakeholders (ibid, p. 319). Parry points out, however, that the ethos of sport, when meeting the wider community, should be understood as an embodied value system that reaches a test, and that it is through the test that the ethos of sport can be sustained (ibid, p. 319).

\footnotetext{
${ }^{1}$ Characterizing sport in this way makes sport, and in particular sports, into what Alasdair MacIntyre calls a practice (MacIntyre, Alasdair, After Virtue).
} 
Let us exemplify this idea of sport having an effect upon the overall society via the ethos of sport in the following way. Through participation in sport, especially in the younger years, a sportsperson meets the specific demands of sport in the form of character traits, rules, norms, and moral principles determining how to act in sport. We can call these character traits, rules, norms, and moral principles the internal values of the sport; through participation in sport, a sportsperson internalizes these values (MacIntyre, 1985). Since sport is one of several supported social practices, it must by necessity consist of values that are also understood as important for society overall. There are, for instance, principles such as the equality principle, which says that sportspersons are of equal value qua human beings, and the principle of abiding by the law. These principles are reflected in sport movement's idea of fair play. Furthermore, there are certain character traits, such as generosity, fairness, endurance, respectfulness, and courage, which are thought to be central for acting in a moral way in sport. They are also highly valued in society at large.

This means that understanding sport as a social practice implies that it is associated with a form of value system, an ethos of sport, which participants acquire through their sporting practice. Furthermore, this ethos of sport carries values that are of importance for the whole society, which implies that sportspersons are optimal as role models as well when it comes to moral attitudes and behavior.

\section{The ethos of sport: The principle of fair play}

There is, therefore, a notion of an ethos as the system of values in sport, and the idea that the ethos of sport should be understood as the basis for thinking that sportspersons should be moral role models for other members of the society, and as Parry points out, especially for younger people (Parry, 2010, p. 320).

To be able to analyze the extent to which sportspersons really should be understood as moral role models, we now need to get an understanding of what the actual ethos of sport consists of. Generally, the ethos of sport can be identified by two elements: a rule governed value structure ultimately connected to the basic principle of fair play in sport, and secondly, a virtue-governed value structure ultimately leading back to the acquisition and personification of certain ethically good character traits.

When it comes to fair play, Sigmund Loland argues that sport rests upon two different principles of fair play: formal fair play and informal fair play (Loland, 1998, p. 83). According to Loland, formal fair play is playing according to the established rules, and informal fair play is concerned with the attitude one has towards the participation in the game as such (ibid, p. 83). When it comes to formal fair play, which Loland calls the fairness norm (ibid, p. 83), he believes it basically consists of a sort of contractual agreement between free agents that should, since they are participating freely in a rule governed activity, follow the rules. He formulates the fairness norm as follows:

"When voluntarily engaged in sport competitions, keep the shared ethos of the practice as long as the ethos does not violate basic, ethical principles and includes a sense of fairness" (ibid, p. 90).

Disregarding the blatantly circularity involved, there are two important aspects that need to be pointed out in the fairness norm. Firstly, by claiming that it is in accordance with the ethos, Loland wants to claim that not all rule violations are negative for a sport. The basic idea is that we can make a distinction between different forms of acts in relation to a rule-governed activity such as sport. Certain acts are simply permissible in that they are in accordance with the rules. Other acts violate the rules, but are still acceptable, since they are considered to be unavoidable in the sporting situation. Certain acts are simply unacceptable per se (ibid, p. 87), and what the ethos of sport prescribes is only that the last form of act is inconsistent with the fairness norm.

Secondly, the idea of not violating basic ethical principles is simply the idea that there are general ethical principles. Loland calls them "natural duties" (ibid, p. 88) ${ }^{2}$ that are not bound by a practice. If a

\footnotetext{
${ }^{2}$ The question is, of course, how these more general values come about, according to Loland, since they are supposed to be beyond the different practices, and not even based upon them. But since the aim of this paper is only to show that
} 
particular sport has an ethos with practice-specific values, we should only act in accordance with the ethos of the sport in so far as it is consistent with these more general values (ibid, p. 88). With this idea about basic ethical principles, Loland maintains that it is only intentional rule violations that are ethically not justified, not any rule violation as such, since it is only intentional rule violations that "represent a violation of the moral contract underlying the fairness principle" (ibid, pp. 88-90).

So, summarizing the formal aspect of the fair play principle underlying the ethos in sport, we can say that it is a principle that a participant internalizes through freely entering the sport activity. Moreover, the basic underlying idea is that participants in sport should act in accordance with the rules of the game.

This article will now turn to the informal aspect of fair play. Loland's view is that just keeping the formal rules of a game is not enough for playing fair; it is also required that the participation is based on a certain attitude. The idea is that a competition, regardless if it is a football game or a marathon, should be good competition in that it has an air of interest to it, and therefore be both predictable as well as unpredictable (ibid, pp. 99-101). However, to enable this openness towards the outcome, a fundamental attitude of the participant needs to be serious in the participation, and try to do his or her best to win. But given the earlier established fairness norm, striving to win has to be in line with the rules. It is further assumed that all opponents act in accordance with this attitude to the game or competition. As Loland describes it, there is a play norm that says that when persons are "voluntarily engaged in sport competitions, play to win!" (Loland, 1998, p. 99). All in all, the very abstract idea of fair play in sport becomes, according to Loland, the two principles:

"The fairness norm: When voluntarily engaged in sport competitions, keep the shared ethos of the practice as long as the ethos does not violate basic, ethical principles and includes a sense of fairness" (ibid, p. 99).

and

"The play norm: When voluntarily engaged in sport competitions, play to win!” (ibid, p. 99).

Given this more procedural or abstract notion of fair play, there are certain principles that we might understand to be of value in sport. First, keeping, obeying, or acting in accordance with the given and established rules isof foremost importance. Every sport has specific rules, and these rules provide the frame of meaningful and legal activity. Second, there is a clear principle involving the idea of always performing to the best of your ability. As a sportsperson, when you enter the arena or stadium, you have a moral duty to perform at your best, or at least to do your best at that particular moment. You ought to try to win, to play at your best. Third, treat all other participants, including yourself, as equal persons with the same rights, and hence deserving your respect. Since your performance depends upon the other person's performance, an underlying principle of mutual respect and equality of value underlies sports competition.

\section{The ethos of sport: Virtues}

So far, this article has discussed the formal notion of fair play involved in the ethos of sport and some of the basic principles that follow from it. However, as has already pointed out, the ethos of sport does not simply consist of formal procedural rules with derivable principles. A fundamental moral element in the ethos of sport is the system of character traits or virtues that are exemplified in sporting behavior. One way of understanding the relation between the fair play principle and these character traits of the ethos of sport is that the positive character traits of sportspersons do not necessarily have to be directly derivable from the fair play of sport, but they must at least be in accordance with fair play.

The idea of a virtue is, basically speaking, a positive quality of a person that helps the person relate to the world in a morally good way. It is in, and through, the virtues that persons determine moral issues and

sportspersons should not be considered as role models, the question of the nature of these natural duties has to be postponed for a later occasion. 
out of which they act in moral situations, since the virtues are, in a sense, embodied moral dispositions that have been internalized into the person through practical and reflective habituation in different moral situations. The virtues are always habitual in the sense that they are acquired, and they form (a part of) the basis of a person's moral judgment.

The list of virtues that are of importance in sport and sporting competitions can be very long, since different positive character traits can be described in a variety of ways as well as on different descriptive levels. In the following, I will only describe some rather general virtues that are part of the ethos of sport (and I leave it to the reader to fill out the behavioral traits that fall under these more general characterizations). Though not being in anyway a complete list, the following virtues are of prime importance in sport: 1. Respectfulness, 2. Fairness, and 3. Endurance (See, for instance, Parry, 2010, pp. 316-326).

1. Let us first look at respectfulness. This virtue is directly derivable from the formal fair play principles discussed earlier. However, respectfulness should not only be understood in relation to respecting other participants of the sport in question. It goes beyond such an all-inclusive respect for other persons involved in the sport, such as coaches, officials, the audience, and, one can say, even to the sport and the sporting community itself. Furthermore, respectfulness should also be considered in relation to oneself. This means that not only it is morally good to act respectfully to other persons and their needs, but a sportsperson should also act respectfully to himself or herself. In a sense, this is a form of virtue representing the Kantian maxim that one should never treat a person only as a means to an end, but always as an end in itself (Kant, 1997, p. 55). Respectfulness can, however, be linked to other virtues, such as friendship, generosity, and tolerance.

a) A very important aspect of human life is the social dimension, especially close friendship, which is both supportive and enhancing. It is thought that, through its collective and social elements, a perfect environment in which a sportsperson meets other persons and friendships can be established, as well as an environment in which friendships flourish in that sportspersons are supportive of each other's development (as both sportspersons are human beings). Friendship enabled by sport is equally strong in team sports and in many individual sports. It can extend from local to global in that sport is built around competitions that take initially place on the local level, then are geographically extended, and in the end involve the whole world. For instance, we can see friendship between many of the female heptathlon athletes in a World Championship or during the Olympic Games. They support each other, and celebrate each other's successful performance as if they had succeeded themselves.

b) Generosity, as a virtue in sport, resembles friendship in many ways. It does not confine itself to the closeness to, or joyfulness over, a friend's success, but is an overall emphatic and supportive feeling for the well-being of anyone that participates in sport and sports competition. For instance, it can consist of lending an opponent equipment so that a game or race can be fairer. In this we can understand generosity to be partly derived from the underlying idea of fair play, which says that opponents are to have equal opportunities to perform well, so that the game or race will be won by the person who plays best to win. A famous historic case of generosity was the German long jumper Lutz Long, who gave his opponent Jesse Owens advice to jump some centimeters away from the take-off board in his last attempt in the qualifying round of the long jump in the 1936 Olympic Games. This helped Owens, who then qualified for the final, which he later won against Long, who came in second (ESPN, Retrieved 13-05-12).

c) The virtue of tolerance, as the general virtue of respectfulness, is directed at both sporting opponents and other individuals involved in the sporting activity. The clearest example in which we can see this type of virtue is, of course, related to referees and sport officials, when athletes or sportspersons accept their judgment. But, it is also exemplified in different sports, when people from different cultures or ethnicity, and people with different sexual preferences, show respect for one another's differences and similarities. On the club level in contemporary football, for instance, people from many different cultures and people with different ethnicities play in the same club, which means that they are focused on the same 
goal, i.e., play to win. Hence, they have to cooperate based upon tolerance of their possible dissimilarities. In the 2012-2013 season, a club such as Manchester United had as many as 15 different nationalities on their 27-man squad. There were four different nationalities out of the six persons in the coaching staff (Svenska Fans, Retrieved 12-11-06).

2. Fairness is a notion that has a rather wide meaning. As a virtue, it can mean both that sportspersons are honest in their competing and that they strive for justice in the competitive moments. For example, Klose showed these elements of fairness in the aforementioned example when he informed the referee that his goal was unintentional foul play and should therefore not be accepted. He acted honestly by informing the referee about the actual state of affairs when the referee was mistaken, and this was done out of the underlying idea that a game should be based upon just evaluations. Another famous example of a sportsperson showing the virtue of fairness is the case of the Swedish tennis player Mats Wilander. In the French open, he was judged to have won the last point of the game, but he claimed that the opponent's ball was in, and therefore demanded that the point should be played once more.

3. The last virtue to be discussed in this context is endurance. Sportspersons acquire a positive characteristic, very helpful for life outside the sporting arena, of not giving up and pressing to attain specified goals or aims. Every sporting person learns that it is only through hard serious work that one is really doing one's best. Usually it is also with the acceptance of pain that one can reach one's aim in the sporting career. Furthermore, sportspersons learn through sport that hard work can and should be in accordance with rules and regulations and should be accompanied by a positive attitude. So, sporting persons discipline their bodies and minds and habituate themselves to endure hard work.

This implies that through participating in sport, sportspersons learn to act in their sporting practice in accordance with rules that are in line with the fair play principle, both written rules such as the laws and rules of sport as well as informal norms such as treating others equally and respectfully. They also acquire positive character traits, i.e., virtues, which enable them to pursue the sporting practice in morally good ways. Furthermore, by learning to follow rules and to acquire the virtues, sportspersons are also becoming more and more morally good in relation to the values of society, since the values of the sporting practice are basically no different than the values of society. Hence, it is thought that sport is an arena, even a privileged one, for moral education, and sportspersons can serve as moral role models.

\section{The ethos of sport: sport practice}

This article has, up to this point, concentrated on the official perspective on sport and moral role models. Let us now look more closely into the actual actions and behavior that do take place in the sports community. Let us see if it is still correct to think that sport is a good arena for moral education, and if sportspersons should be considered moral role models. I will divide this into separate sections based upon four very common cases in sport. In these cases, neither the formal fair play principle is followed nor was the informal fair play norm followed. What these examples show is that sporting practice is not an arena in which sportspersons acquire positive moral standards; hence, sporting practice indicates that sportspersons should not be considered moral role models.

\section{Case A: Violating the rules when profiting from it}

In many sports, especially in team sports, it is very common to intentionally break the rules of the game when sportspersons or their teams are somehow supposed to profit from it. The most common of these cases is the so-called strategic rule violation, for instance, in football or ice hockey, in which a sportsperson consciously commits an infraction of the rules because the situation requires such an act. For instance, a hockey player consciously hooks another player to stop the first player from scoring. Another common strategy, used in 1500 metre track racing, is to push and use the arms both to protect a position and to gain advantage while attempting to get a new position, especially in the latter part of the race. 
The strategic rule violation has a few characteristics. First, the rule-violating act in itself is known to the participants to be illegitimate in relation to the rules and regulations of the sport. Second, strategic rule violations are always intentional in that they are done based upon a choice. Third, strategic rule violations are done for the purpose of gaining an advantage in the game situation (which one attains just because it is ruled out as a non-permissible action). In relation to what was claimed earlier about permissible acts according to the ethos of sport, strategic rule violations are acts that are unacceptable per se (Loland, 1998, p. 87), as they are aiming at a conscious violation of the fundamental agreed upon method of performance in sport.

Now, someone might argue that the strategic rule violation that occurs in sport is not really a problem that could imply that sportspersons are not good moral role models. First, the rules of particular sports are constructed in such a way that they foresee the use of strategic foul play, and thereby have settled penalties for breaking the rules in strategic rule violations.

For instance, in ice hockey, tripping is against the rules and has the established penalty:

A player who shall place his stick, leg, foot, arm, hand or elbow in such a manner that it shall cause his opponent to trip or fall shall be assessed, at the discretion of the Referee,

a: > Minor penalty (2')

or

$>$ Major penalty + Automatic Game Misconduct penalty $\left(5^{\prime}+\mathrm{GM}\right)$

or

$>$ Match penalty (MP) (IHHF, p. 81)

But, there is a special kind of interpretation of tripping that is done in the case of a player who is free:

"In a "Breakaway" situation, when a player, in "Control of the puck" outside his own defending zone with no opponent to pass other than the goalkeeper, is tripped from behind, thus preventing a reasonable scoring opportunity, the Referee shall award to the non-offending team, a: > Penalty Shot (PS)" (ibid, p. 81).

That is, in the rulebook of ice hockey and also in other sports, even though both of these rules could be applied to cases of conscious as well as unconscious rule violations, a form of protection from using violations of the rules as a strategic plan for success is built into the system. In this way sport itself gives the foundation for sportspersons to acquire a rule-governed behavior, and gradually internalize the associated values of sport such as playing in accordance with the rules. Second, since strategic rule violations are ruled out by the explicit rules of sport, sportspersons who violate them accept that there is a form of penalty following the violation.

These possible counterarguments miss two facts. Firstly, though it is true that sport is associated with these kinds of regulations of strategic rule violations, and that sportspersons play in accordance with some of the rules, it is not the case that sportspersons, in critical or strategic situations, normally play according to the rules. There is almost always some major or minor foul play involved, such as slashing or holding in ice hockey, pulling the shirt or tripping in football, or pushing in a 1500 metre race. Secondly, though the sportsperson might accept a penalty associated with a strategic violation, the sportsperson wants to avoid the penalty. That is, even though the player knows that he or she has made something wrong according to the rules, the player tries as much as possible to avoid anybody observing that it really was a foul play. Furthermore, if we consider how sportspersons, coaches, and sport commentators talk about these strategic rule violations, it becomes even more obvious that they are part of the game as such. For instance, talking about "good penalties," "necessary rule violations," and "taking a penalty for the team" are all examples of the fact that strategic rule violations are something that is involved in sport itself. This means that sportspersons, rather than acquiring favorable moral standards and behavior, acquire strategic behavior and standards implying that the end justifies the means, and are not, qua sportspersons, to be regarded as moral exemplars in society. As Kosiewicz claims, "The main and the most important purpose of competition (...) is 
not strict adherence to the rules of the competition, but the optimal use of their content in order to achieve success" (Kosiewicz, 2011, p. 38).

\section{Case B: Not doing your best when gaining from it}

As pointed out earlier, one of the more central aspects of fair play in sport is the idea that one should always do one's best; that is, play to win. But if we look at the actual practice of sport, it does not seem to be the case that sportspersons are always taught to follow that idea if there is an overriding benefit from their lesser performance.

Let us look at some actual cases. The first case is the 2006 Olympic Game hockey tournament in Torino. In their last qualifying round, the Swedish ice hockey team was in a position to "choose" opponents for the quarterfinal. Depending on a victory or a defeat in the game against Slovakia, they would stand against what was considered a stronger or a weaker team in the quarterfinal. In the case of victory, they would have had to face teams such as Russia and Canada; if they lost, they would have faced Switzerland, which was thought to be a much more weaker team than both Russia and Canada. The game against Slovakia was lost 0-3. Sweden went on to win against Switzerland 6-2, eventually winning the gold medal by defeating Finland in the final by the score 3-2. Sweden had won the gold medal for the second time in the Olympic Games ice hockey tournament. But the legacy of the game against Slovakia was that Sweden had been throwing the game, by not really trying to perform at their best. They simply did not play to win, as the fair play ideal implies. Though it has never really been proven that the Swedish team actually threw the game, there have been several insinuations against the Swedish team of just that. In an interview on a television program, one of the lead players of the Swedish team, Peter Forsberg, implied that the players did not really perform their best due to the knowledge of the situation in the groups (Gill, 2011). Then, at least some facts prove that violations of the ideal of playing to win in all situations occur when the circumstances are such that the sportsperson benefits from not doing his or her best.

Another case of participating and consciously not doing one's best is to be found in running. Let us have a look at the sprinter Usain Bolt. In the qualifying rounds of the World Championship and the Olympic Games, Bolt was not performing at his best. For the last 30-40 meters, he was not running at his highest performance, but slowly decreased his speed when he knew he would qualify for the next round. Of course, it is not only Bolt who does this: it is the common behavior of all sportspersons in short track running. And, it is behavior that is similar in several different sports, such as running at different distances, long jump, triple jump, etc. You do not try to perform at your best, you simply do what you are required to do and nothing more, because that is what you benefit from.

The last case is what has been known as the badminton scandal in the 2012 London Olympic Games (Walker \& Siddique, 2012). None of the badminton players Ha Jung-Eun, Kim Min-Jung, Jung, KyungEun and Kim Ha-na from South Korea, Yu Yang and Wang Xiaoli from China, and Meiliana Jauhari and Greysia Polii from Indonesia played to win. It was also a case in which the interest of the players was more focused upon who they would meet in the next round, rather than focusing on performing at their best. In the case of the badminton players, there is no question whatsoever of whether they consciously failed to do their best. Even some of the coaches admitted there were instances of trying to throw the game. As a result, all of the above players were disqualified from the tournament.

Now, someone might argue that the basic problem in these cases are not in relation to the sportspersons not trying to do their best, but rather that there is a vagueness associated with the notion of "doing one's best in a game." First, all of the cases mentioned above can easily be understood as strategic planning of the game, where the overall ambition is to do the best in the meaning of winning a competition. In this sense, there is a vagueness concerning what constitutes the game. Is a game always a singular occasion, or is a game the overall series, tournament, or a league consisting of several different singular games? In sport, it might be argued, it is more rational to understand a game as the overall tournament in relation to a sportsperson performing at his or her best. The reason is simply that a very important feature of 
sport is that of becoming the winner of the gold medal and is what is in the focus of a sportsperson's participation. Second, there is also a vagueness concerning what it is that one should do at one's best. Tactics and strategic planning concerning the strength and energy of the body and the mind is part of the performance in sport. Hence, it might be argued that doing one's best also includes a strategic managing of the powers of the mind and body so that they will be at peak when really needed. That is, tactics and strategic planning with the aim of winning the overall competition or tournament should not be understood as a break of the principle of doing one's best, but rather as a normal and absolutely acceptable behavior in sport. Hence, it might be argued, the fact that sport has several cases where sportspersons seems to act as if they do not perform at their best when they can benefit from it, is no real argument against the fact that sportspersons should be understood as moral role models.

Now, it is true that sport comes with this vagueness concerning game and tournament, and even what "doing one's best" mean in sport. But I still think these cases of not doing one's best when gaining from it is problematic. The reasons are first, this way of acting strikes at the center of moral education of sport in that it violates the fundamental fair play principle. That is, from the moral fairness point of view, not doing one's best simply is morally outrageous in the sporting context. Secondly, not doing one's best is also problematic in that it is a form of diminishing and disrespectful behavior towards the opponent. Simply put, it fails to acknowledge the opponent as being an individual or a team with the same dignity and value as oneself, since one is using the opponent as a simple mean for one's own desires and needs. Third, when it comes to the virtue of endurance, the throwing of games or competitions are also problematic, since this undermines the idea of rewarding the person who deserves it through hard practice, commitment, and dedication to the sport. In not doing one's best when gaining from it, a person tries to take an easy way to success, instead of relying upon true commitment and dedication to the sport. Hence, given these three arguments why failing to do one's best when gaining from it in sport is problematic for sport as a practice of moral education. It is reasonable to think that sportspersons should not, qua sportspersons, be understood as moral role models.

\section{Case C: Acting against your own better knowledge when gaining from it}

Earlier, I claimed that sport provides an arena for sportspersons to act in such a way that they consciously break the rules when gaining from it. Now, we will look at a related problem with sport: that sportspersons, through participating in sport, are taught to act against their own better judgment if they think they can benefit from it.

As already mentioned, besides the fair play principle in sport, several important virtues that are in line with the fair play principle are also thought to be central in the fostering of sportspersons due to their participation in sport. One of those important virtues is honesty, or truthfulness in the sense of holding to the truth. The basic idea is that sportspersons are honest, in the sense that they act in accordance with what they know to be the case. But, if we look at how sportspersons do act in performing their sports, it is the regular behavior of sportspersons to act exactly opposite to what they know is true when they think they can benefit from doing so; it is instead exceptional cases that sportspersons stick to the truth in relation to their actions.

Let us start with an obvious example, football. A football game consists of many different challenges between players. Assume that two players are competing for the ball, and the ball goes out of bounds, leading to a throw-in. What happens in several cases is that both players lift up their hands as markers that they should be given the throw. And, of course, there are very tricky situations in which both players actually might think that they rightly should be given the throw. But, and this is the point, most cases of this kind are such that one of the players really knows, and knows for certain, that they were the last person to touch the ball before it went out, and hence, that he or she does not really deserve to be given the throw. But still, he or she acts as if the throw should be given to him or her. This is, I think, a very basic form of action taken in football, and also in other sports such as handball, floor ball, etc. It is a conscious action taken to deliberately fool the referee in such a way that the sportsperson benefits from the decision of the referee. 
Furthermore, if we look at volleyball, this deliberate cunning behavior has become a form of integral part of the ritual for the players. As an example we can take a case of a smash in volleyball. The attacking team makes a smash, and the defending team is putting up a block to defend the smash. Most of the times, both teams starts celebrating winning the point by gathering in a circle, not even awaiting the call by the referee. But, there are reasons to believe that one of the teams already knows, or at least have information implying, that the opponent team actually won the point.

Lastly, the case of doping in sport can be understood as a form of acting against your own better knowledge when gaining from it. The assumption is of course that, as a sportsperson, you are supposed to be playing according to the rules, including the anti-doping rule. Now, a person who is using doping does so to increase his or her performance. But, this means that the person who is doped knows for certain, unless he or she is tricked into taking doping, that he or she is participating and doing the performance in the sporting competition on false premises. And celebrating success or even participation in itself based upon this knowledge of being doped is a pure form of acting against your own better judgment when gaining from it.

This indicates that sport, contrary to the idea of being a fruitful environment for acquiring the virtue honesty or truthfulness, seems to be a setting in which people are taught to try to be not honest or not truthful when they think they gain from acting in a deceiving way. And, what is also important, the behavior of acting against your own better judgment when gaining from such an action is not confined to elite sport, professional sport, or even senior sport. It is a form of behavior that exists on all kind of levels: from the Premier League in football to the last amateur division in the Swedish football league, from senior floor ball to junior floor ball and children floor ball, etc. Doping is, of course, banned in sport, but the fact that doping occurs, and even that there is a need in sport to have a special anti-doping committee controlling sportspersons on a regular basis, implies that sport is really a setting where we should not expect to find individuals that are moral role models due to being sportspersons.

\section{Case D: Expression of derogatory attitudes in sport when gaining from it}

The last case is, as honesty, related to sportspersons very often not acting in accordance with virtuous behavior, but instead the opposite. The virtues respect and tolerance are claimed to be at the heart of sport. They are something that sportspersons acquire through their participation in sport. Though there are several, even many, cases of respectful and tolerant behavior amongst sportspersons, such as making the referee aware of an injury to an opponent by kicking the ball out of bounds, or helping opponents perform better by giving advice during competition such as in the high jump. There are also many cases in which sportspersons act disrespectful and intolerant towards other sportspersons.

The first case is simply the trash talk particularly prevalent in team sports such as football, ice hockey, floorball, basketball, and handball. During a game there is constant chatter between players, who by addressing each other in a consistently coarser way try to make their opponent lose their temper, become unfocused, or simply get back in such a way that the referee notices it and gives the opponent a penalty. The terms used in this kind of trash talk are derogatory in nature and center around attributing the opponent as being weak by using terms such as "pussy," "bitch," or "fatty," or stupid by attributing terms such as "idiot," "asshole," or "wanker." Very often the terms are of sexual character, and also very often referring to the female sex. Sometimes the trash talk is of more complex nature, such that a player talks negatively about relatives of another player, not uncommonly sisters, the wife or the mother of the player, or non-verbal in the form of gestures of a derogatory nature. But whether the trash talk is simplistic or complex, verbal or nonverbal, the underlying attitude is derogatory in nature and therefore disrespectful and intolerant in nature. The disrespect and intolerance are used as means for gaining benefits in the games.

Now, some might argue that this is something that occurs in team sports and that it is not really representative for sport as such. To this point I would like to counter that trash talk does not seem to be used only in team sports such as football, but seems to exist in sports where opponents have the possibility to communicate with each other. An example is cross-country skiing. The Swedish cross-country skier 
Charlotte Kalla said in an interview in the Swedish tabloid Aftonbladet that there is much trash talk during the races, and that she uses this strategy due to the "competition-devil" in her (Thorén, 2013). And, as in the team sport cases, the basic idea of using derogatory attribution to opponents is to make them unfocused, thereby gaining an advantage in a race.

A second case of derogatory attitude in sport is the attitude towards teammates. This might sound a bit odd, but it is not uncommon, for instance in football, that players either say derogatory things to their own teammates, or act with gestures of a derogatory nature towards their own teammates. The benefit gained from this behavior is not normally in relation to the aim of winning a game or a competition, but rather to boost one's own ego or make one's self look better in the eyes of others through implying that mistakes are not made by oneself, but by the teammates ${ }^{3}$. The basic idea, then, is behavior that is both disrespectful and intolerant towards others in character and that a sportsperson consciously uses for some sort of personal benefit.

But attitudes of a derogatory nature are not simply confined to the actual setting of the game or match. It might even be that most of the negative attitudes in relation to sport are expressed before, in between, or after games or matches. A classic example is, of course, Muhammad Ali's ego boosting before his fights, saying very negative things about the opponent. But similar attribution that can be made on the pitch today is also made in traditional media, which is sometimes eager to foment hostility or hostile behavior between opponents ${ }^{4}$. Social media has created a new forum for this form of disrespectful and derogatory expression.

What this shows us is that in sport, respectful behavior towards opponents is something that we should not expect to be the most common behavior. On the contrary, when gaining from bad behavior, such as discrediting your opponent or calling the opponent bad names, etc., this is what very often takes place. This means, then, that when it comes to virtues such as respectfulness, tolerance, and even generosity it is not the case that sport provides an optimal moral educational setting. On the contrary, sportspersons, by participating in sport, are taught to act in non-generous, intolerant, and disrespectful ways. This implies that we do not have any reasons to think that sportspersons should be understood to be moral role models.

\section{Conclusion}

As has been shown in this paper, sport and the sporting community have been attributed, and have been claimed by themselves, to be a particularly good social environment in which moral education can take place, and that sportspersons, due to their participation in sport, should be understood as moral role models for other persons in society. The basic reason for this is the idea of the ethos of sport, consisting of the principle that sport is based upon fair play and that doing sport means acquiring a number of virtues and acquiring a good character.

In this paper we have now seen that there are several normal cases in sporting practice that really undermine this idea of sportspersons being moral role models. The basic reasons for this assumption are that, contrary to what has been assumed by the sporting community and philosophers of sport, the actual practice of sport cannot be understood to be based upon a fair play principle, participating in sport does not give sportspersons morally good character through their acquisition of virtuous behavior, and that sport is simply not a good basis for moral education. Sport, then, has no necessary internal relation to ethics. Sport is just

\footnotetext{
${ }^{3}$ Allegations of this kind of behavior have been addressed towards the football player Zlatan Ibrahimovic by at least one former teammate. See, for instance, the article "Materazzis känga till Zlatan: ’Det är aldrig hans fel” by Frändén och Karlsson (Frändén, Karlsson 2013).

${ }^{4}$ A typical example is the way in which the Swedish media, especially tabloids, are fomenting an alleged hostility between the cross-country skiers from Sweden and Petter Northug from Norway. For examples, see, for instance, the article "Hellners revanch efter norske stjärnans hån" by Flinck (Flinch, 2010), and the article "Thorén: Ouppfostrat och ovärdigt av Northug” by Thorén (Thorén, 2013).
} 
one of the social fields in which people meet and act, and it is even a social field in which behavior normally thought to be morally bad many times is promoted and sometimes even institutionalized. And thinking that sport has an internal relation to morality and good character thought claiming that sport is built upon fair play and the acquisition of virtues behavior is much more of describing a hope, an ideal, than a real element in the nature of sport. This does not mean, of course, that sportspersons cannot be morally good persons, or that sportspersons cannot act morally good, or that some sportspersons cannot be moral role models. There are sportspersons who are morally good, and they are of course excellent moral role models. But we should not confuse good moral character with some sportspersons, with sport being a morally good educational environment. The fact that some sportspersons are acting morally and have a morally good character is not because they are fostered in sport; rather, it is that they are acting good and are virtues despite the fact that they are sportspersons. They are, in that case, moral role models even though they are sportspersons.

\section{REFERENCES}

ESPN (Retrieved 12-11-06) Owens Pierced a Myth. by Schwartz, L. http://espn.go.com/sportscentury/features/00016393.html.

Flick, J. (2010). Hellners revanch efter norske stjärnans hån /The revench of Hellner after the mockery by the Norwegian star/. In Aftonbladet. From http://www.aftonbladet.se/sportbladet/vintersport/os2010/article12180865.ab. Retrived 13-05-12.

Frändén, J., Karlsson, K. (2013). Materazzis känga till Zlatan: "Det är aldrig hans fel" /Materazzis criticism of Zlatan: "It is never his fault" $\%$ In Aftonbladet. From http://www.aftonbladet.se/sportbladet/fotboll/internationell/italien/article16110163.ab. Retrieved 22-01-13

Gill, S. (2011). Forsberg: Slovakien var en läggmatch /Forsberg: The game against Slovakia was a thrown game/. In Expressen. From http://www.expressen.se/sport/hockey/tre-kronor/forsberg-slovakien-var-en-laggmatch/ retrieved 130512

IIHF (Retrieved 12-11-06). International Ice Hockey Federation, http://www.iihf.com/fileadmin/user_upload/PDF/rules_part_two.pdf.

Kant, I. (1997). Grundläggningen av sedernas metafysik/Fundamental Principles of the Metaphysics of Morals/. Translated from german by Retzlaff, J. Göteborg: Daidalos

Karlsson, E. (2012). Klose erkänner - då ändrar sig domaren /Klose admits - and the referee changes his decision/. In Aftonbladet. Retrieved 2012-09-29, from http://www.aftonbladet.se/sportbladet/article15510896.ab.

Karlsson, K. (2012). Klose hyllas efter fair play-gesten /Klose is praised after the fair-play act/. In Aftonbladet. Retrieved 2012-09-29, from http://www.aftonbladet.se/sportbladet/fotboll/internationell/italien/article15512455.ab.

Kosiewicz, J. (2011). Foul Play in Sport as a Phenomenon Inconsistent with the Rules, yet Acceptable and Desirable. In Physical Culture and Sport. Studies and research. Vol. LII, DOI: 10.2478/v10141-011-0012-x.

Loland, S. (1998). Fair Play: Historichal Anachronism or Topical Ideal? In M.J McNamee, S.J., Parry (Eds.). Ethics and Sport. London: Spoon Press.

MacIntyre, A. (1985). After Virtue: a Study in Moral Theory. London: Routledge.

Parry, J. (2010). Sport, Ethos and Education. In M. McNamee (Ed.) The Ethics of Sport: A Reader. London: Routledge.

Plato (1939). Faidon/Phaidon. In Fem Dialoger i folkupplaga /Five Dialogues in peoples edition/. Stockholm: Hugo Gebers Förlag

Plato (1993). Staten /The Republic/. Nora: Nya Doxa

Thorén, P. (2013). "Det skriks mycket" Charlotte Kalla om skällsorden i skidspåren /"There is a lot of trash talk" Charlotte Kalla about the bad language at the racing tracks/. In Aftonbladet. From http://www.aftonbladet.se/sportbladet/vintersport/skidor/article16011817.ab. Retrieved 23-01-13

Thorén, P. (2013). Thorén: Ouppfostrat och ovärdigt av Northug /Thorén: Bad Manner and disgraceful of Northug/. In Aftonbladet. From http://www.aftonbladet.se/sportbladet/vintersport/skidor/article16287400.ab. Retrived 130512

Walker, P., Siddique, H. (2012). Eight Olympic Badminton Players disqualified for "Throwing Games". In The Guardian. From http://www.guardian.co.uk/sport/2012/aug/01/london-2012-badminton-disqualified-olympics, Retrieved 13-05-12

http://www.svenskafans.com, (Retrieved 12-11-06). 
AUTHOR'S ADDRESS:

Roger Melin

Department of Philosophy

School of Humanities and Media

Högskolan Dalarna

79188 Falun, Sweden

Email: rme@du.se 